\title{
O BRINCAR DAS CRIANÇAS NA ESCOLA EM TEMPO INTEGRAL: TENSÕES ENTRE AS FRONTEIRAS TERRITORIAIS E AS CULTURAS INFANTIS
}

\author{
THE CHILDREN'S PLAYING IN THE SCHOOL IN FULL TIME: TENSIONS \\ BETWEEN THE TERRITORIAL BORDERS AND CHILDREN'S CULTURES
}

\author{
Alessandra Amaral Ferreira \\ Mestre em Gestão Integrada do Território pela UNIVALE \\ Secretaria Municipal de Educação - SMED. \\ Governador Valadares, Minas Gerais - Brasil. \\ alessandraamaralf@ hotmail.com \\ Maria Celeste Reis Fernandes de Souza \\ Doutora em Educação pela UFMG \\ Professora da Universidade Vale do Rio Doce - UNIVALE. \\ Governador Valadares, Minas Gerais - Brasil. \\ celeste.br@gmail.com
}

\begin{abstract}
Resumo: O artigo se sustenta na defesa da educação integral em tempo integral na Educação Infantil e visa contribuir para ampliar o debate nesse campo, ao tomar como objeto o brincar das crianças de 5 anos, em uma escola municipal, na qual elas permanecem 8 horas diárias. Como questão norteadora, indaga-se sobre as configurações do brincar dessas crianças na Escola em Tempo Integral. O referencial teórico estabelece um diálogo com autores da Sociologia da Infância que reconhecem a centralidade do brincar como constitutivo das culturas infantis, e autores do campo da Geografia que tematizam território e territorialidade. Participam do estudo 22 crianças e, para capturar as configurações do brincar, foram utilizados para a coleta dos dados: observação do cotidiano da escola, análise de documentos e rodas de conversa com as crianças. A análise coloca em evidência as tensões entre as culturas infantis e as fronteiras territoriais que buscam conformar o brincar das crianças na Escola em Tempo Integral (ETI). Os resultados indicam a forma escolar presente nas configurações do brincar e os escapes propiciados pelas práticas do brincar na imbricação território/territorialidade. As conclusões permitem refletir sobre a necessidade de reconhecimento, no tempo integral, de que o brincar é parte da cultura infantil, tem centralidade na infância e, portanto, é um direito das crianças.
\end{abstract}

Palavras-chave: Brincar. Educação infantil. Tempo integral.

\begin{abstract}
The article is based on the defense of full-time integral education in early childhood education and aims to contribute to broadening the debate in this field by taking as object the playing of the 05 years old children in a municipal school, in which they remain 08 hours daily. As a guiding question, one inquires about the configurations of these children's playing in the Full Time School (ETI). The theoretical framework establishes a dialogue with authors of the Sociology of Childhood who recognize the centrality of the playing as constitutive of children's cultures, and authors of the field of Geography that discuss territory and territoriality. Twenty-two children participated in the study and, in order to capture the settings of the play, the data used were collected from daily observation of the school, analysis of documents and conversation groups with children. The analysis highlights the tensions between children's cultures and territorial borders, which seek to conform the playing of children in the ETI. The results indicate the school form present in the settings of the playing and the escapes, propitiated by the practices of the playing in the territory/territoriality imbrication. The conclusions allow us to reflect on the need for full-time recognition that playing is part of the culture of children, has a centrality in childhood, and therefore is a right of the children.
\end{abstract}

Keywords: Playing. Child education. Full-time.

Para citar - (ABNT NBR 6023:2018)

FERREIRA, Alessandra Amaral; SOUZA, Maria Celeste Reis Fernandes de. O brincar das crianças na escola em tempo integral: tensões entre as fronteiras territoriais e as culturas infantis. Eccos - Revista Científica, São Paulo, n. 56, p. 1-19, e11234, jan./mar. 2021. Disponível em: https://doi.org/10.5585/eccos.n56.11234. 


\section{Introdução}

A ampliação do tempo diário de permanência de crianças e adolescentes na escola comparece no campo legal há mais de duas décadas, na Lei de Diretrizes e Bases da Educação Nacional (LDBEN) (BRASIL, 1996) que, em seu art. 34, estabelece: “a jornada escolar no Ensino Fundamental incluirá pelo menos quatro horas de trabalho efetivo em sala de aula, sendo progressivamente ampliado o período de permanência na escola" (BRASIL, 1996).

No cenário brasileiro, a partir de 2007, acompanhamos o esforço de ampliação da jornada diária escolar, com o lançamento do Programa Mais Educação (PME), que propiciou, na última década, diferentes experiências no País e ampliou o leque dos debates sobre a educação escolar: na atenção às diferentes aprendizagens éticas, cidadãs, políticas, estéticas, culturais, que compõem o sentido da integralidade da formação humana; no reconhecimento do direito ao tempo integral na equalização das desigualdades educacionais, especialmente para grupos vulneráveis; na necessidade de um maior diálogo da escola com a cidade, conforme se pode conferir em diferentes documentos disponíveis no sítio eletrônico do Ministério da Educação (MEC).

Ao longo dos últimos 10 anos, a Educação Infantil vem sendo incluída nesse debate. Os argumentos de diferentes autores reafirmam o seu lugar como primeira etapa da Educação Básica. Reconhecem as crianças como sujeitos de direitos. Preocupam-se com as vulnerabilidades das infâncias brasileiras e destacam a necessidade de que práticas educativas no tempo diário a mais na escola (tempo integral), para além das tradicionais 4 horas diárias (tempo parcial), reconheçam a diversidade das infâncias brasileiras e suas culturas, os tempos infantis e os direitos das crianças (MOLL, 2012; BARBOSA; RICHIE; DELGADO, 2015; ARAÚJO, 2015a; SEVERINO; BAUER, 2015; SARDENBERG, 2017).

$\mathrm{O}$ atual Plano Nacional de Educação (PNE), que estipula diretrizes, metas e estratégias para a política educacional até 2024 , admite a necessidade brasileira de universalização da Educação Infantil em sua primeira meta e prevê, na meta 06, "oferecer educação em tempo integral em, no mínimo, 50\% (cinquenta por cento) das escolas públicas, de forma a atender, pelo menos, $25 \%$ (vinte e cinco por cento) dos (as) alunos (as) da educação básica" (PNE, 2014, p.26), incluindo, portanto, a Educação Infantil.

Acena-se, pois, no Brasil, para uma intencionalidade de oferta do tempo integral, ainda que em meio aos imbróglios para a universalização da Educação Infantil e das dificuldades de equalização entre universalização e ampliação do tempo de escola, que requer investimentos 
estruturais, em recursos humanos, projetos político-pedagógicos, dentre outros (ARAÚJO, 2015a; PEIXOTO; SCHUCHTER; ARAÚJO, 2015b).

Se a oferta de educação em tempo integral não é exatamente uma novidade na Educação Infantil brasileira e se pensarmos no caráter assistencialista que historicamente tem constituído a educação das crianças em creches e pré-escolas (ARAÚJO, 2015b; BARBOSA; RICHIE; DELGADO, 2015), há que se reconhecer, nesse cenário, sua colocação como ponto de pauta na agenda pública e os consequentes tensionamentos a esse viés assistencialista.

Tais tensionamentos têm sido forjados nos debates sobre a educação integral em tempo integral, como temos acompanhado na última década no Brasil, além de em um conjunto de dispositivos legais sobre a educação das crianças em creches e pré-escolas na atenção dada às infâncias como sujeitos de direitos. Se por um lado esse arcabouço teórico e legal reafirma a importância da garantia desse direito, por outro, evidencia dilemas, tensões e controvérsias na ampliação da jornada em tempo integral, postos ora pelo modo como se elege grupos prioritários como demandatários da oferta em tempo integral, ora pelas próprias mazelas da educação pública brasileira, que se fazem sentir fortemente na Educação Infantil (ARAÚJO, 2015b; MAURÍCIO, 2015).

A intenção deste artigo ${ }^{1}$, construído na defesa da educação integral em tempo integral na Educação Infantil, é contribuir para ampliar o debate nesse campo, ao tomar como objeto o brincar das crianças em uma escola municipal de um município de médio porte do estado de Minas Gerais, cuja política pública implantada em 2009 universalizou a jornada diária de 8 horas para todas as crianças e todos os adolescentes matriculados na Educação Infantil e no Ensino Fundamental, em todas as 50 instituições educacionais das zonas urbana e rural, por meio da Escola em Tempo Integral (ETI).

Ancoradas em autores que defendem a centralidade do brincar como parte constitutiva das culturas infantis, estabelecemos diálogo com outros autores que tematizam a Educação Integral e autores que discutem o território, buscando capturar como as crianças brincam no cotidiano da escola. Trouxemos para a nossa discussão, neste texto, as tensões que identificamos entre as culturas infantis e as fronteiras territoriais que buscam conformar o brincar das crianças na ETI.

\footnotetext{
${ }^{1}$ Pesquisa aprovada por um Comitê de Ética em Pesquisa (CEP). Processo número 2.390.040.
} 


\section{Brincar das crianças no tempo integral - escolhas teóricas}

Discutir a centralidade do brincar nas interações e práticas escolares não é uma novidade, posto que em diferentes documentos elaborados para a Educação Infantil, o brincar se faz presente como eixo estruturante das demais atividades e constitutivo da infância (BRASIL, 1998; BRASIL, 2010; BRASIL, 2012). O que nos parece relevante, neste artigo, é compreender a importância do brincar no tempo a mais de escola, reconhecendo o direito do brincar na proposição do tempo integral, nas experiências que se organizam na escola ou em articulação com outros equipamentos sociais

[...] externos à escola, tais como: centros sociais, bibliotecas comunitárias, parques e clubes. Na formação das culturas infantis, ocorre também a configuração das territorialidades infantis, pois, nela, estão presentes as interações entre os lugares destinados às crianças pelo mundo adulto e suas instituições. (SARDENBERG, 2017, p.31).

Parece natural evocar o brincar no tempo integral em experiências organizadas em articulação com os territórios da cidade. $\mathrm{O}$ ambiente desses espaços favorece as interações e as brincadeiras e pela saída dos muros da escola imprime outros movimentos às lógicas escolares.

Mas, em experiências de turno único estendido, como a ETI, que se articulam exclusivamente no espaço escolar, com saídas ocasionais pela cidade, amplia-se, também, o tempo do brincar? Ou são colocadas em cena outras lógicas para a educação das infâncias que relegam o brincar a práticas pontuais nas escolas?

Os argumentos que se constroem, ao se colocar em pauta o tempo integral na Educação Infantil, é o de que o brincar é parte da construção das culturas infantis e é por meio dele que as crianças arquitetam seus mundos (ARAUJO, 2015a; SARDENBERG, 2017).

Desse modo, a educação integral em tempo integral é desafiada a criar uma aproximação com as culturas infantis, posto que a jornada escolar ampliada assume atividades e tempos da infância que tradicionalmente não eram vistos como dever da escola, como, por exemplo, a "experiência do brincar espontâneo, autônomo e intergeracional" (SARDENBERG, 2017, p.33). Portanto, ao ampliar o tempo na escola para as crianças, como consequência, deve-se ampliar, também, as condições e oportunidades para as brincadeiras.

Ao refletir sobre o brincar das crianças em uma escola na qual elas permanecem 8 horas diárias, assumimos a perspectiva da Sociologia da Infância. Essa escolha teórica nos provoca a considerar a criança como produtora de cultura e ator social, assumindo, desse 
modo, a necessidade de escuta das suas vozes e escolhas, reconhecendo a sua participação ativa nos diversos contextos sociais nos quais se inserem.

Os teóricos que estudam a criança por esse viés nos apresentam uma abordagem que colabora para o reconhecimento da criança como sujeito ativo que participa da sociedade contemporânea. Essa abordagem possibilita compreender a criança como sujeito que interage em diferentes segmentos sociais e que, por meio de suas brincadeiras e interatividades, constrói identidades individuais e coletivas, constituindo uma cultura própria (CORSARO, 2011; DELGADO; MULLER, 2005; SARMENTO, 2004, 2015).

Sarmento (2004) propõe quatro eixos estruturadores das culturas da infância: a interatividade, a ludicidade, a fantasia do real e a reiteração. Conforme argumenta o autor, a interatividade é um dos eixos estruturadores da infância. $\mathrm{O}$ mundo da criança é diverso. Ela convive com diferentes realidades com as quais adquire e constrói valores, novas condutas e estratégias que contribuem para a construção de sua identidade individual e social.

Outro eixo mencionado por Sarmento (2004) é a fantasia do real; o denominado faz de conta. Ao fantasiar, as crianças significam o mundo que as rodeia. No mundo infantil, a fantasia e o real se encontram indissociáveis e "este processo de imaginação do real é fundacional do modo de inteligibilidade" (SARMENTO, 2004, p.16, grifos do original), por meio do qual a criança faz uma "transposição imaginária de situações, pessoas, objetos ou acontecimentos" (IDEM). Desse modo, as crianças constroem seus mundos atribuindo outros sentidos às situações vividas.

Outro elemento de base da cultura infantil é a reiteração. $O$ tempo da criança pode ser reiniciado e repetido, pois é um processo contínuo, gerando sempre novas experiências. $\mathrm{Na}$ convivência com as crianças, podemos observar como elas repetem o que foi transmitido por seus pares, assim como suas próprias ações, em um tempo recursivo.

Em nosso estudo, destacamos a ludicidade e essa tem um traço central nas culturas infantis; as crianças brincam continuamente. O brincar e o brinquedo são para as crianças elementos de base na recriação do mundo, na produção das fantasias infantis e na constituição de suas culturas. O autor afirma que "o brincar é a condição da aprendizagem, da sociabilidade. Não espanta, por isso, que o brinquedo acompanhe as crianças nas diversas fases da construção das suas relações sociais" (SARMENTO, 2004, p.16).

Ao propor uma agenda para a educação da infância em tempo integral, Sarmento (2015) postula a escola infantil como um lugar de encontro das culturas, e o brincar é 
considerado como um direito aliado a outros direitos, como proteção, cuidado, saúde, natureza etc.

Reconhecendo que o brincar, como inerente às crianças e expressão cultural das infâncias, incorpora os demais eixos estruturantes (fantasia do real, interatividade e reiteração), e tem o seu acontecer em "um lugar", como nos mostra o livro "Territórios do Brincar” (MEIRELES, 2015), buscamos refletir um pouco mais sobre o território.

Autores do campo da Geografia (CLAVAL, 2007, 2008; HAESBAERT, 2007; SACK, 2013) utilizam o termo território atestando que as experiências humanas inscritas nos lugares são de ordem simbólica e cultural. O território é, pois, constituído pelos valores, pelas práticas, pelos modos como nos apropriamos dele, pelos gestos, pela memória, pelas regras, pela linguagem, pelos meios empregados pelas pessoas para a sobrevivência e, refletindo sobre as crianças e suas culturas, também pelo brincar.

As crianças são crianças onde quer que estejam e têm a capacidade de transformar os espaços por elas frequentados em territórios (o pedacinho do quintal, o quarto, uma pequena varanda, um cantinho da casa, o parque, a rua, os espaços das escolas etc.). Se refletirmos sobre as crianças com as quais nos deparamos cotidianamente, podemos afirmar que elas brincam e se rememorarmos as suas brincadeiras, poderemos evocar apropriações espaciais que elas fazem nesse ato. A prática do brincar está presente até mesmo nos momentos e lugares em que o adulto avalia como não apropriado para brincadeiras.

Cabe, pois, reconhecer uma apropriação pelas crianças do território no brincar que se conforma na imbricação território/territorialidade. Para Haesbaert (2007), as territorialidades devem estar sempre associadas à concepção de território correspondente. $\mathrm{O}$ teórico afirma que a territorialidade está imbricada em relações culturais, pois está "intimamente ligada ao modo como as pessoas utilizam a terra, como elas próprias se organizam no espaço e como elas dão significado ao lugar" (HAESBAERT, 2007, p.27).

Sack (2013) afirma que "territorialidade é sempre construída socialmente. Ela assume um ato de vontade e envolve múltiplos níveis de razões e significados" (p.87). É, pois, no modo de apropriação do território que se constituem as territorialidades e que se supõe o controle da área por um grupo. Por isso, inerente ao território e às territorialidades, encontram-se as relações de poder (HAESBAERT, 2007; SACK, 2013).

Tendo como referência os diferentes autores citados nesta seção, ao tomarmos como objeto de discussão o brincar das crianças da Educação Infantil na ETI, reconhecemo-las como protagonistas de suas histórias, participantes ativas da sociedade e produtoras de 
cultura. Admitimos que elas se apropriam do território, por meios das territorialidades. As crianças empreendem ações que influenciam e, ao mesmo tempo, controlam as relações sociais nos territórios, do mesmo modo que respondem aos cerceamentos que lhes são feitos no território escolar.

\section{0 brincar das crianças na escola em tempo integral}

$\mathrm{Na}$ ETI, encontravam-se matriculadas em creches, à época da realização do estudo, 6.047 crianças e na pré-escola, 4.793, totalizando 10.840 matrículas em tempo integral na Educação Infantil ${ }^{2}$.

O campo de pesquisa é uma escola dessa rede, escolhida intencionalmente por se situar em um bairro periférico, conhecido na cidade pela vulnerabilidade social e por atender exclusivamente a crianças da Educação Infantil. Encontravam-se matriculadas nessa escola, no período de coleta de dados, 410 crianças na faixa etária de 1 a 5 anos e 11 meses de idade.

Os sujeitos da pesquisa são 21 crianças (10 meninos e 11 meninas) de uma turma de 5 anos de idade ${ }^{3}$, sendo que 16 delas pertencem a famílias demandantes do Programa Bolsa Família ${ }^{4}$, o que reafirma as condições de vulnerabilidade do bairro.

Para capturar o brincar das crianças, foram utilizados como procedimentos para a coleta dos dados empíricos: observação do cotidiano da escola; levantamento de documentos para melhor compreender a rotina das crianças ${ }^{5}$; participação em brincadeiras com as crianças; rodas de conversa.

Estudiosos da Sociologia da Infância promovem reflexões sobre os processos metodológicos que concebem a participação das crianças nas pesquisas como sujeitos de conhecimento sobre si mesmas e indicam os modos como suas falas devem ser interpretadas e inseridas nos trabalhos acadêmicos, sempre dando voz ao sujeito que fala (DELGADO; MULLER, 2005; CORSARO, 2011).

Corsaro (2011) reafirma a importância de se considerar a criança como produtora de cultura e também a percepção que se deve assumir na pesquisa, reconhecendo a reciprocidade, na qual "as crianças afetam e são afetadas pela sociedade" (CORSARO, 2011, p.57). Por isso, a importância da escuta sensível das crianças e a valoração do protagonismo infantil.

\footnotetext{
${ }^{2}$ A pesquisa de campo foi realizada de setembro a novembro de 2018. Em 2021 encontram-se matriculadas em tempo integral na Educação Infantil 9.638 crianças: 4.635 em creches e 5.003 na pré-escola. Dados atualizados fornecidos pela Secretaria Municipal de Educação (SMED), março, 2021.

Dentre as 5 turmas de crianças dessa faixa etária, foi escolhida uma que apresentasse maior equiparação de gênero.

${ }^{4}$ O Programa Bolsa Família é um programa de transferência direta de renda com condicionalidades. Foi criado pelo Governo Federal, no ano de 2003 , fazendo parte da política do Programa Fome Zero, buscando beneficiar famílias em situação de pobreza ou de extrema pobreza. Dentre os principais objetivos desse Programa está o de promover o acesso à Educação. Disponível em:

http://www.mds.gov.br/webarquivos/publicacao/bolsa_familia/Cartilhas/Cartilha_PBF_2015.pdf. Acesso em: 24 jan. 2019.

${ }^{5}$ Foram consultados a ficha informativa das crianças, quadros de horários com distribuição das atividades e o Projeto Pedagógico da escola.
} 
Inspiramo-nos, portanto, nessas contribuições teóricas. Uma das pesquisadoras responsáveis pela coleta dos dados se inseriu no campo de pesquisa e nas interações com as crianças no espaço escolar, nas brincadeiras e nas rodas de conversa, se empenhando em realizar a pesquisa com crianças e não sobre crianças.

As crianças permanecem na escola das 7 horas às 15 horas. Essa jornada é distribuída em atividades em salas de aula denominadas "salas referência" e em outros ambientes na escola, como parque, brinquedoteca, pátio, quadra e campo de futebol. Na implantação e implementação da ETI foram feitos investimentos "em mudanças no interior das unidades escolares, de forma que (...) pudessem oferecer condições compatíveis com a presença de alunos e professores em turno integral" (CAVALIERE, 2009, p.52). Portanto, essa é uma experiência centrada no espaço escolar e não contempla em suas diretrizes a utilização intencional de outros equipamentos sociais na composição do tempo integral, como se pode depreender em uma leitura do Projeto Pedagógico da escola.

A escola se organiza em turmas, observando a faixa etária, e cada turma tem uma sala como referência. É nessa sala que as crianças chegam todos os dias e realizam a roda de conversa para depois se movimentarem para outros espaços da escola. A maior parte do tempo de cada turma é vivenciado na sala referência, pois é nesse ambiente que a turma guarda seus pertences, realiza seu repouso, a roda de conversa, atividades dirigidas pela professora e aguarda seus responsáveis para o momento de ir embora.

Ao observar e acompanhar o cotidiano das crianças nessa escola durante as 8 horas de atividades diárias, participar das suas brincadeiras quando era convidada por elas (ou quando elas permitiam) e integrar as rodas de conversa ${ }^{6}$, foi possível produzir um material empírico no qual se pode conferir a preponderância do brincar nos diferentes momentos vividos pelas crianças: nos tempos e espaços reservados para o brincar, realizado como parte das atividades escolares; no horário de entrada na escola; nos momentos de saída da sala de aula ao final da aula; ao se deslocarem de um espaço para outro (da sala referência para o refeitório, por exemplo). Pode-se concluir, que essas crianças brincam constantemente na escola. Na experiência do brincar, elas se apropriam do território, na imbricação território/territorialidade, imprimem nele suas marcas, como uma expressão da cultura infantil, mas também encontram cerceamentos - fronteiras que tendem a controlar suas ações e relações.

\footnotetext{
${ }^{6}$ As observações foram registradas pela pesquisadora de campo em um caderno de pesquisa e foram feitas gravações em áudio das brincadeiras (quando possível) e das rodas de conversa ( 08 rodas que tematizaram as brincadeiras no parque). Para a análise, as gravações foram transcritas.
} 
No território escolar é possível identificar fronteiras que, segundo Sack (2013), podem ser visíveis e invisíveis. Nesse ambiente, permeado de relações sociais e culturais, há limites que são estabelecidos tanto por parte dos adultos, quanto da própria arquitetura escolar, ou pelo modo de organização escolar.

Se por um lado essas fronteiras buscam cercear o brincar das crianças, por outro, as crianças também escapam ou contornam esses obstáculos, a partir de ações criativas e estratégicas, constituindo suas territorialidades pelo brincar. As fronteiras que cerceiam as brincadeiras e o modo como as crianças escapam delas evidenciam as tensões com as culturas infantis, que serão objeto de análise nas próximas seções intituladas: "Já acabou a brincadeira?”, “Tem que pegar a chave no parque.", “Ô tia depois você vem!”

\section{1 "Já acabou a brincadeira?"}

A pergunta que abre esta seção foi registrada no diário de campo, em uma das idas com as crianças ao parque e foi feita por $\mathrm{Ana}^{7}$ que, indignada, interpelou a professora, quando ela informou que o tempo para brincar no parque havia terminado. A interpelação de Ana foi seguida pelos seus pares que fizeram eco ao seu questionamento, reafirmando o desejo de continuarem brincando.

A interpelação foi feita após os 50 (cinquenta) minutos destinados ao brincar, que recortam as atividades cotidianas na ETI. O brincar é, pois, limitado pelo fator tempo, mesmo quando se tem mais tempo na escola, o que restringe as brincadeiras. Tanto nessa situação quanto em outras observadas, não foi realizada negociação com as crianças para que elas tivessem um pouco mais de tempo para o brincar.

Esse é um cerceamento comum na ETI, como foi possível acompanhar. Assim, o brincar constitutivo das culturas infantis é limitado por fronteiras. Retomando as contribuições de Sack (2013), pode-se refletir que o ato de interromper a brincadeira "porque o tempo acabou" é uma fronteira territorial, ainda que sem demarcações espaciais físicas, por isso, invisível, mas cujos efeitos são visíveis no exercício do controle das territorialidades. O autor argumenta que a territorialidade é uma "tentativa, realizada por um indivíduo ou grupo de afetar, influenciar, ou controlar pessoas, fenômenos e relações, ao delimitar e assegurar seu controle sobre certa área geográfica. Essa área será chamada de território” (SACK, 2013, p.76).

\footnotetext{
${ }^{7}$ Nome fictício utilizado para preservar a identidade dos sujeitos.
} 
O teórico afirma a existência de fronteiras para o controle da área que podem se apresentar como visíveis, como é o caso das demarcações socioespaciais, como uma parede, por exemplo, ou fronteiras entre países; ou invisíveis, mas cujos efeitos limitam as ações do sujeito no território, implicando, pois, nas territorialidades. $O$ autor destaca que a territorialidade, o modo de apropriação do território por pessoas ou grupos

[...] deve conter uma forma de comunicação, que pode envolver um marco ou um sinal, como geralmente é encontrado em um limite ou fronteira. Ou uma pessoa pode criar um limite através de um gesto, como apontar. Um limite territorial pode ser a única forma simbólica que combina uma declaração sobre a direção no espaço e uma declaração sobre a posse ou exclusão. (SACK, 2013, p.80).

Acompanhando a rotina da escola, foi possível constatar que, no dia a dia, delimitamse os tempos e espaços para as brincadeiras e interatividades das crianças, estabelecendo, pois, limites territoriais e, consequentemente, buscando controlar as territorialidades, como se pode conferir no quadro a seguir, afixado na sala de aula:

Quadro 1 - Rotina da Turma de 5 Anos

\begin{tabular}{|c|c|c|c|c|c|}
\hline HORÁRIO & $\begin{array}{l}\text { SEGUNDA- } \\
\text { FEIRA }\end{array}$ & $\begin{array}{l}\text { TERÇA- } \\
\text { FEIRA }\end{array}$ & $\begin{array}{l}\text { QUARTA- } \\
\text { FEIRA }\end{array}$ & $\begin{array}{l}\text { QUINTA- } \\
\text { FEIRA }\end{array}$ & $\begin{array}{l}\text { SEXTA- } \\
\text { FEIRA }\end{array}$ \\
\hline $07: 00$ às $07: 20$ & Acolhida & A colhida & Acolhida & Acolhida & Acolhida \\
\hline $07: 20$ às $08: 10$ & Atividade & A tividade & Atividade & Atividade & Atividade \\
\hline $08: 10$ às $08: 30$ & Lanche & Lanche & Lanche & Lanche & Lanche \\
\hline $08: 30$ às $09: 20$ & Campo & A tividade & Atividade & Atividade & Atividade \\
\hline $09: 20$ às $10: 10$ & Atividade & A tividade & Atividade & Atividade & Atividade \\
\hline $10: 10$ às $10: 50$ & Atividade & Quadra & Atividade & Atividade & Brinquedoteca \\
\hline $10: 50$ às $11: 20$ & Pátio & A tividade & Parque & Sala de Dança & Vídeo \\
\hline $11: 20$ às $11: 50$ & Almoço & Almoço & Almoço & Almoço & Almoço \\
\hline $11: 50$ às $13: 00$ & $\begin{array}{l}\text { Escovação/ } \\
\text { repouso }\end{array}$ & $\begin{array}{l}\text { Escovação/ } \\
\text { repouso }\end{array}$ & $\begin{array}{l}\text { Escovação/ } \\
\text { repouso }\end{array}$ & $\begin{array}{l}\text { Escovação/ } \\
\text { repouso }\end{array}$ & $\begin{array}{l}\text { Escovação/ } \\
\text { repouso }\end{array}$ \\
\hline $13: 00$ às $13: 20$ & $\begin{array}{l}\text { Organização } \\
\text { da Sala }\end{array}$ & $\begin{array}{l}\text { Organização da } \\
\text { Sala }\end{array}$ & $\begin{array}{l}\text { Organização da } \\
\text { Sala }\end{array}$ & $\begin{array}{l}\text { Organização da } \\
\text { Sala }\end{array}$ & $\begin{array}{l}\text { Organização } \\
\text { Sala }\end{array}$ \\
\hline $13: 20$ às $14: 00$ & Atividade & A tividade & Atividade & Atividade & Atividade \\
\hline $14: 00$ às $14: 20$ & Lanche & Lanche & Lanche & Lanche & Lanche \\
\hline $14: 20$ às $14: 50$ & Atividade & A tividade & Atividade & Atividade & Atividade \\
\hline $14: 50$ às $15: 00$ & $\begin{array}{l}\text { Preparo para a } \\
\text { saída }\end{array}$ & $\begin{array}{l}\text { Preparo para a } \\
\text { saída }\end{array}$ & $\begin{array}{l}\text { Preparo para a } \\
\text { saída }\end{array}$ & $\begin{array}{l}\text { Preparo para a } \\
\text { saída }\end{array}$ & $\begin{array}{l}\text { Preparo para } \\
\text { saída }\end{array}$ \\
\hline
\end{tabular}

Fonte: Dados da pesquisa de campo (2018). 
O que se pode observar no quadro de horários acima é uma rotina organizada em 8 horas de atividades diárias, na qual os tempos e espaços do brincar são limitados por uma "forma escolar" (VINCENT; LAHIRE; THIN, 2001). Assim, em 4 dias da semana são destinados 50 minutos para o brincar livre das crianças (no pátio, na quadra, no parque e na brinquedoteca) e em 1 dia da semana não se reserva tempo e espaços para o brincar, o que faz com que uma das crianças desabafe com sua mãe no momento de saída da escola: "Não gostei da escola. Não teve parque (João)".

Sarmento (2015) e Barbosa, Richie e Delgado (2015), ao discutirem o tempo integral na Educação Infantil, apresentam preocupações com a "forma escolar" que, segundo os autores, nega as culturas infantis, legitima a condição das crianças como alunos e desconsidera a dimensão da educação integral que abarca diferentes experiências e aprendizagens, nas quais a ludicidade é parte integrante.

A “forma escolar", definida por Vincent, Lahire e Thin (2001), é marcada, na escola moderna, por uma relação pedagógica entre um professor e seus alunos, em um espaço concebido para tal, "a escola" e por "um tempo específico, o tempo escolar, simultaneamente como um período de vida, como tempo no ano e como emprego do tempo cotidiano" (p.13).

A função reguladora do tempo escolar, historicamente adaptado do tempo fabril (FILHO; VAGO, 2001), é um tempo artificial que marca o Ensino Fundamental no Brasil e que, no modo de organização da ETI, alcança a Educação Infantil e impõe limites temporais às práticas do brincar. Araújo (2015b) nos alerta para um dos dilemas da incorporação da Educação Infantil à Educação Básica e que se estende ao tempo integral, "parece estar ocorrendo uma contaminação da educação infantil pelo ensino fundamental do que o inverso, como desejávamos" (p.171).

Sarmento (2015) defende a educação integral em tempo integral como constitutiva dos direitos da criança, portanto, “fora da 'forma escolar', centrada na criança, nas culturas infantis, na ludicidade e criatividade e na ampliação das possibilidades de experiência do mundo" (SARMENTO, 2015, p.68, grifos do original).

Há, pois, uma tensão permanente entre o tempo da escola, tomado do modo como se organiza a ETI no Ensino Fundamental, como se pode conferir em documentos orientadores ${ }^{8}$, com o tempo da criança, que é recursivo (SARMENTO, 2004), não controlado pelo relógio ela é capaz de brincar de novo... de novo... de novo... ou se perder no brincar que não pode, pois, ser controlado em módulos-aula de 50 minutos.

\footnotetext{
${ }^{8}$ Referência à matriz curricular proposta pela SMED e em vigência em 2017 e 2018.
} 
Acompanhando o cotidiano da escola, constata-se que as práticas do brincar normalmente são planejadas pelas professoras nos espaços do parque, quadra, pátio e brinquedoteca. A rotina tem um tempo previsto para cada ambiente; significa que a criança tem 50 minutos para viver suas experiências em cada espaço. $\mathrm{Na}$ maioria das vezes, as brincadeiras são interrompidas porque o tempo que o adulto estabelece nem sempre é o mesmo tempo da criança.

Nos tempos/espaços do parque e da brinquedoteca quase sempre as brincadeiras são escolhidas pelas crianças e seus pares. Na brinquedoteca, o mundo de faz de contas se confunde com o real; no parque, além das crianças usarem os brinquedos, elas entram no mundo da imaginação, ao escolherem, preferencialmente, o tanque de areia - esse é um lugar sempre ocupado pela imaginação infantil.

Nesse brincar, pode-se capturar "a fantasia do real" (SARMENTO, 2004), eixo estruturante das culturas infantis, fazendo parte da vida da criança, da sua construção de visão de mundo e de como atribui significado às coisas. Diferentemente do mundo adulto, na cultura infantil, a fantasia e o real se confundem - no brincar de casinha, de heróis e princesas, de personagens de desenhos animados, de festas etc. - como foi possível acompanhar no campo de pesquisa.

$\mathrm{Na}$ quadra e no pátio sempre acontecem brincadeiras dirigidas ou sugeridas pelas professoras. Observamos, para as brincadeiras dirigidas nesses espaços, o uso de cordas, bolas, legos, figuras geométricas, bolinhas de sabão e até mesmo os piques que, algumas vezes, são propostos pelas professoras. Entretanto, em todos esses tempos/espaços o fator tempo é cerceador. No auge das brincadeiras, entra o adulto em cena e diz: "acabou o tempo".

Sarmento (2004) destaca que "a natureza interativa do brincar das crianças constitui-se como um dos primeiros elementos fundacionais das culturas da infância" (p.16). Assim, o brincar é inerente à criança, é do corpo, da imaginação, é cultural e imprevisível. Por isso, as crianças criam escapes do tempo escolar.

Na sala referência, o brincar acompanha o cotidiano - as crianças inventam sempre, imaginam com o que têm em mãos - e, nos deslocamentos diários entre os espaços na escola, organizadas em fila, as crianças brincam na fila ou dela se desviam correndo para escorregar no corredor ou nas rampas de acesso; outras põem a mão no ombro do colega representando um trenzinho; ou se abaixam para pegar objetos como tampinhas, pedaços de giz de cera e os transformam em brinquedos. Esticam como podem o tempo do parque, da quadra e do pátio 
com estratégias diversas (não respondem prontamente ao adulto, procuram os brinquedos, continuam a brincar, a despeito de serem informadas sobre o esgotamento do tempo).

As crianças brincam e ultrapassam os limites estabelecidos por meio de ações criativas, apropriando-se do território com o brincar. Elas criam oportunidades para se reinventarem diariamente nos seus espaços, dentre eles a ETI, mesmo na delimitação do tempo escolar.

A experiência no campo de pesquisa nos possibilitou constatar que nas práticas das filas, ou no tempo esgotado, ou nos momentos de atividades dirigidas pelas professoras, as crianças buscam estratégias para driblar as fronteiras territoriais. Nessa tentativa, elas sempre se inclinam para as brincadeiras e interatividades. As crianças forjam aberturas que lhes permitem constituir por meio do brincar, a escola como seu território, controlando elas mesmas a entrada de outros sujeitos nas brincadeiras, ora interpelando os adultos com as perguntas, ora se posicionando na continuidade do brincar e estabelecendo ali territorialidades.

\section{2 "Tem que pegar a chave do parque." - "Ô tia depois você vem!"}

"Ir ao parque é motivo de muita alegria para as crianças, elas correm em direção ao portão, ansiosas para que ele seja aberto" (diário de pesquisa). Essa é uma frase recorrente nos registros feitos no campo de pesquisa. Ir ao parque é um acontecimento aguardado pelas crianças que sempre perguntam se é o "dia de ir ao parque", se "estão indo ao parque", se "tem parque hoje" etc. O parque dessa escola é como o de muitas escolas de Educação Infantil - escorregador, tanque de areia, pneus, gangorra, casinha de madeira etc.

No primeiro dia de acompanhamento das crianças ao parque, ao nos aproximarmos do portão, Pedro diz: "tem que pegar a chave do parque". A recomendação de Pedro, de 5 anos, foi seguida pela espera das crianças e da pesquisadora enquanto a professora buscava a chave. O parque, pois, que é compreendido como "infantil” e espaço do brincar por sua própria constituição, não é de livre acesso para as crianças. O portão fica trancado com o cadeado, diariamente, estabelecendo um limite, nesse caso, uma fronteira visível.

A fala de Pedro nos levou a observar com mais atenção as fronteiras visíveis na própria composição da arquitetura escolar - demarcações espaciais que controlam o acesso das pessoas. $\mathrm{Na}$ escola onde este estudo foi realizado, identificamos como fronteiras visíveis: 
- Portão Central: presença de uma profissional responsável por impedir a saída das crianças desacompanhadas e fazer a necessária identificação das pessoas que têm acesso à escola fora do horário de entrada e saída das crianças.

- Portão do Parque: fica trancado e só é aberto pelas professoras na hora das atividades com as turmas.

- Salas: é a rotina que estabelece o momento em que as crianças podem adentrar as salas (referência, de vídeo, brinquedoteca) ou sair delas. Em todo o deslocamento na escola as crianças são sempre acompanhadas por um adulto.

- Câmeras de vigilância instaladas dentro da escola.

Embora se possa argumentar sobre a questão da segurança das pessoas e das crianças no ambiente escolar, como no caso do portão central, o que chama a atenção é a vigilância e restrição de livre circulação no interior da escola. Assim, a arquitetura da escola e a disciplina escolar se presta à vigilância e ao controle no sentido foucaultiano (FOUCAULT, 2006). O parque se presta à lógica da vigilância, como um espaço cerceado às crianças.

Mas o parque é território da infância e dele as crianças se apropriam, constituindo ali, no brincar, territorialidades que cerceiam, também, a entrada do adulto, como enuncia a recomendação de Flávia e que intitula esta seção - "Ô tia depois você vem!", feita após a tentativa da pesquisadora de organizar uma roda de conversa no parque.

Para as crianças, o parque na escola é território do brincar espontâneo, como nos narra Eckschmidt (2015). A autora nos convoca a olhar com mais atenção as sutilezas presentes no gesto do brincar na areia, nos gravetos, nas pedras, nas folhas, nas tampinhas de garrafa etc., cuidadosamente dispostos pelas crianças e compondo cenários e cenas presentes no faz de conta.

Assim, a proposta da pesquisadora de realizar uma "roda de conversa no parque" foi adiada pela criança e pelas demais que, ignorando a proposta da roda, continuaram a brincar de diversas formas como: empurrar a areia com o pé; fazer buracos com a mão; catar pedrinhas na areia e jogar em outra direção; separar brinquedos etc. A atividade da roda foi deixada de lado pela pesquisadora e pode-se conferir o cerceamento que as crianças fazem da entrada da pesquisadora no território do brincar, estabelecendo uma fronteira que sinaliza o controle daquele território pelas crianças. De posse dele, o transformam pela territorialidade que nele estabelecem por meio do brincar. 
A experiência com o brincar das crianças na ETI nos mostra que elas vão traçando estratégias para a constituição de suas culturas e territorialidades. Dentro da lógica organizacional marcada pela "forma escolar", nas relações sociais, as crianças se deparam com limites, cotidianamente. Contudo, a criança brinca, é um ser ativo, vai construindo possibilidades para suas territorialidades. Elas são criativas: elas brincam, com o copo no bebedouro, com a água do chuveiro, com a colher no refeitório, com as pedrinhas encontradas pelo chão, com um pedaço de papel, com uma tampinha perdida, com a tampa de uma caneta, enfim, um artefato torna-se significativo para a criança e ela brinca constantemente.

Claval (2008) reafirma a importância da cultura na constituição do território e das territorialidades, por meio dos conhecimentos, dos valores, das práticas, das trocas, que conferem ao sujeito "uma identidade pessoal e social" (CLAVAL, 2008, p.26). Pode-se afirmar que as crianças, na construção de suas culturas, se apropriam e transformam criativamente as informações recebidas, reproduzindo o que lhes convém. Elas internalizam a cultura adulta recebida, rejeitam alguns traços e interpretam outros ao seu modo, nas práticas do brincar (SARMENTO, 2004; CORSARO, 2011).

"Ô tia depois você vem!" Ao se dirigir à pesquisadora com essa frase, a criança determina um limite para ela naquele espaço praticado por todas; exerce seu poder de decisão no território que elas já se reconhecem como pertencentes, pois dão a ele identidade, a partir da apropriação e valorização simbólica daquele território, feita pelo grupo. O território é central na vida do ser humano, posto que confere um sentido de pertencimento a um determinado grupo (CLAVAL, 2007) e tem um papel preponderante na constituição das territorialidades.

As crianças deste estudo nos mostram que, mesmo diante de fronteiras visíveis ou invisíveis, elas as tensionam e se apropriam dos espaços escolares por meio do brincar, como pertencentes ao território escolar. Por meio de suas experiências, dentre elas o brincar, desenvolvem suas identidades individuais e coletivas, na cultura de pares. Elas contribuem, assim, para o que podemos denominar, inspiradas em Claval (2007) "paisagens da infância”, deixando impressões de suas ações praticadas no território, imprimindo nele suas marcas culturais. 


\section{Considerações finais}

A ampliação da jornada diária escolar na Educação Infantil como um direito da criança reafirma a importância das culturas infantis e do reconhecimento das crianças como seres ativos, conhecedoras de si mesmas e competentes para interpretar a cultura na qual estão imersas em um processo criativo. O tempo integral tem sentido quando não se transforma em um tempo no qual se repetem práticas, muitas vezes tomadas do Ensino Fundamental, com um viés escolarizante, negando à criança o direito de ser criança. A escola de tempo integral na infância, em experiências que se organizam na escola ou na desejável articulação com os territórios da cidade ou do campo, deve ser reconhecida como território de interação, vivo e de relações, portanto, intenso e dinâmico, potencializado pelas crianças e suas culturas.

No brincar das crianças na ETI, foi possível capturar tensões que se estabelecem entre as fronteirais territoriais pautadas nas delimitações espaciais na escola - visíveis e invisíveis, decorrentes da lógica de organização escolar - e as culturas infantis, nos escapes feitos pelas crianças para o brincar. Posto que o brincar é eixo estruturante das demais atividades na Educação Infantil, ao se falar da criança e do brincar na escola em jornada de tempo integral, é fundamental reconhecer a necessidade de ampliar o seu tempo.

Durante a experiência no campo de pesquisa, foi possível constatar que o brincar é constitutivo das crianças. Entretanto, elas são, também, conduzidas em grande parte pelos adultos, como se fosse necessário ensinar a criança a brincar. Quando nos referimos à préescola, observamos que, nessa fase, a brincadeira consta nos documentos oficiais, mas, no cotidiano da escola, assume intencionalidade pedagógica, em um viés cada vez mais escolarizante. Esse viés requer reflexão, posto que a brincadeira é um direito da criança e faz parte da cultura infantil. Portanto, as crianças de 4 e 5 anos têm o direito de brincar, sendo protagonistas de suas histórias. Cotidianamente, nesse universo entrecruzado de culturas, as crianças constroem identidades individuais e coletivas e constituem seus territórios e suas territorialidades.

Com efeito, os tempos/espaços da Educação Infantil são marcados pelas experiências vividas diariamente pelas crianças, nas quais se estabelecem múltiplas relações: elas relacionam-se entre si e com os adultos, com os artefatos, com os pares, com as culturas. Portanto, aprisionar esse tempo em módulos-aula ou reduzir a poucas horas cotidianas o tempo do brincar, em uma semana de 40 horas, é reproduzir não só um tempo fabril, mas uma lógica que nega o direito à infância. 
Cabe refletir que o tempo na escola é uma construção social vivida pelos sujeitos e suas experiências. Ainda que a escola estabeleça uma organização do tempo para suas atividades, as crianças, sujeitos ativos nesse contexto social, também agem em tempos próprios, atribuindo-lhes múltiplos sentidos e significados. Assumir mais tempo na escola é assumir também os anseios e desejos das crianças; é assumir que o brincar faz parte da cultura infantil e tem centralidade nessa faixa etária.

\section{Referências}

ARAÚJO, V. C. de. (Org.). Educação infantil em jornada de tempo integral. Vitória: EDUFES, 2015a.

ARAÚJO, V. C. . O “tempo integral” na educação infantil: uma análise de suas concepções e práticas. In: ARAÚJO, V. C. de. (Org.). Educação infantil em jornada de tempo integral. Vitória: EDUFES, 2015b, p. 17-56.

BRASIL. Ministério da Educação. Secretaria de Educação Básica. Brinquedos e brincadeiras de creches; manual de orientação pedagógica. Brasília: MEC/SEB, 2012.

Disponível em:

http://portal.mec.gov.br/dmdocuments/publicacao_brinquedo_e_brincadeiras_completa.pdf . Acesso em: 16 mar. 2021.

BRASIL. Lei de Diretrizes e Bases da Educação Nacional. Lei n ${ }^{\circ}$ 9.394/96, de 20 de dezembro de 1996. Disponível em: http://www.planalto.gov.br. Acesso em: 15 mar. 2021.

BRASIL. MEC. Referencial Curricular Para a Educação infantil. v. 1,2 e 3. Brasília: MEC/SEF, 1998. Disponível em: http://portal.mec.gov.br . Acesso em: 14 mar. 2021.

BRASIL. Ministério da Educação. Diretrizes Curriculares Nacionais Para a Educação infantil. Brasília: MEC, 2010. Disponível em: http://ndi.ufsc.br/files/2012/02/DiretrizesCurriculares-para-a-E-I.pdf . Acesso em: 25 out. 2020.

BARBOSA, M. C. S; RICHTER, S. R. S.; DELGADO, A. C., Educação infantil: Tempo Integral ou Educação Integral? Educação em Revista. Belo Horizonte, Vol.31, n 04, p. 95 119, Out/dez. 2015.

CAVALIERE, A. M. V. Escolas de tempo integral versus alunos em tempo integral. In: MAURICIO, Lúcia Velloso (Org.). Em aberto. Brasília: Instituto Nacional de Estudos e Pesquisas Educacionais Anísio Teixeira, v.22, n.80, p. 51-63, 2009.

CLAVAL, P. A Geografia Cultural. 3ª ed. Florianópolis: Ed. UFSC, 2007.

CLAVAL, P., Uma, ou Algumas Abordagem(ns) Cultural(is) na Geografia Humana? In: SERPA, A., (Org.). Espaços culturais: vivências, imaginações e representações [online]. Salvador: EDUFBA, 2008, p. 13-32. Disponível em: http://books.scielo.org . Acesso em: 15 dez. 2019. 
CORSARO, W. A. Sociologia da Infância. $2^{\mathrm{a}}$ ed. Porto Alegre: Artmed, 2011.

DELGADO, A. C.; MÜLLER, F. Sociologia da infância: pesquisa com crianças. Educ. Soc. Campinas, Vol. 26, n 91, Maio/Ago. 2005. Disponível em http://www.scielo.br/pdf/es/v26n91/a02v2691.pdf. Acesso em: 15 mar. 2021.

ECKSCHMIDT, S. O brincar na escola entre tantos caminhos. In: MEIRELLES, R. (Org.) Território do Brincar: diálogo com escolas. São Paulo: Instituto Alana, 2015. p.70 - 75

FILHO, L. M. F.; VAGO, T. M., Entre relógios e tradições: elementos para uma história do processo de escolarização em Minas Gerais. In: VIDAL, D. G.; HILSDORF, M. L. S. (Orgs.). Brasil 500 Anos: Tópicas em História da Educação. São Paulo: Universidade de São Paulo, EDEUSP, 2001, p. 117-136.

FOUCAULT, M. Vigiar e Punir: nascimento da prisão. 31. ed. Petrópolis: Vozes, 2006.

HAESBAERT, R. Território e multiterritorialidade: um debate. Geografia. Ano IX. N. 17, 2007, p. 19-46.

MAURÍCIO, L. V. Educação integral e(m) tempo integral na educação infantil: possibilidade de um olhar inovador. In: ARAÚJO, V. C. de. (Org.). Educação infantil em jornada de tempo integral. Vitória: EDUFES, 2015, p. 89-122.

MEIRELLES, R. (Org.). Território do Brincar: diálogo com escolas. São Paulo: Instituto Alana, 2015.

MOLL, J. (Org.). Caminhos da educação integral no Brasil: direito a outros tempos e espaços educativos. Porto Alegre: Penso, 2012.

PEIXOTO, E. M., SCHUCHTER, T. M., ARAÚJO, V.C.. O “tempo integral” na educação infantil: financiamento, gestão e projeto político pedagógico em questão. In: ARAÚJO, V. C. de. (Org.). Educação infantil em jornada de tempo integral. Vitória: EDUFES, 2015, p. 123160 .

SARMENTO, M. J. As culturas da infância nas encruzilhadas da $2^{\mathrm{a}}$ modernidade. In: SARMENTO, M. J.; CERISARA, A.B. (Org.). Crianças e miúdos: perspectivas sócio pedagógicas da infância e educação. Porto: Asa, 2004, p. 9-34.

SARMENTO, M. J. Para uma agenda da educação da infância em tempo integral assente nos direitos da infância. In: ARAÚJO, V. C. de. (Org.). Educação infantil em jornada de tempo integral. Vitória: EDUFES, 2015, p. 57-88.

SACK, R. Significado de territorialidade. In: DIAS, L. C.; FERRARI, M. (Orgs.)

Territorialidades humanas e redes sociais. $2^{\mathrm{a}}$ ed. rev. Florianópolis: Insular, 2013. p.19-113. 
SARDENBERG, A. (Coord.). Educação integral nas infâncias: Pressupostos e práticas para o desenvolvimento e a aprendizagem de crianças de 0 a 12 anos. Centro de Referências em Educação Integral. 2017.

SEVERINO, A. J.; BAUER, C., O Plano Nacional de Educação (PNE) e a Educação infantil. ECCOS - Rev. Cientifica. São Paulo, n 37, p. 11 - 16, maio/Ago. 2015. Disponível em: https://periodicos.uninove.br/eccos/article/view/5829/2995 Acesso em: 13 mar. 2021.

VICENT, G.; LAHIRE, B.; THIN, D., Sobre a história e a teoria da forma escolar. Educação em Revista. Belo Horizonte, n 33, p. 07-47, jun. 2001. 